Fecha de recepción: octubre 2019

Fecha de aceptación: diciembre 2019

Versión final: diciembre 2021

\section{La identidad en el turismo religioso de San Juan de los Lagos}

Adrián Antonio Cisneros Hernández ${ }^{1}$, Marcela del Rocío Ramírez Mercado ${ }^{2}$ y Juan Ernesto Alejandro Olivares Gallo ${ }^{3}$

Resumen: El turismo religioso o turismo de peregrinación es una de las actividades que genera una derrama económica considerable en el estado de Jalisco. Uno de los sitios de gran relevancia con el que cuenta el estado es el municipio de San Juan de los Lagos, que tiene más de 400 años con la celebración del 2 de febrero la llamada fiesta de la candelaria y que llega a recibir cerca de 700 mil peregrinos de diferentes partes de México y extranjeros. Por tanto, su actividad genera o propicia una identidad que se refleja en los recursos gráficos aplicados para la promoción, comunicación y difusión de productos o servicios del lugar, estos muestran un estilo ecléctico que brinda una personalidad que se evidencia en las características particulares de sus visitantes, los cuales agregan una variedad de matices, ya que provienen de distintas clases sociales. Así mismo se integra la personalidad de sus habitantes que son de distintas comunidades, los cuales influyen en la identidad del pueblo. Es interesante identificar y analizar la manera en que se constituyen las dimensiones que construyen la identidad del municipio, mediante lo verbal, la cultura, los objetos, así como las piezas gráficas que visten al municipio.

Palabras clave: Turismo religioso - Identidad - Estilo ecléctico - Elementos gráficos - Códigos estilísticos.

[Resúmenes en inglés y portugués en las páginas 66-67]

(1) Adrián Antonio Cisneros Hernández: Egresado de la Licenciatura en Diseño para la Comunicación Gráfica y Maestría en Diseño y Desarrollo de Nuevos Productos del Centro Universitario de Arte, Arquitectura y Diseño. Se desempeña como Profesor de Asignatura en la Universidad de Guadalajara, en el Centro Universitario de Arte, Arquitectura y Diseño en donde Imparte en la Licenciatura de Diseño para la Comunicación Gráfica, asignaturas de Taller de Diseño, Computación y multimedia. Mail: adrian.chernandez@ academicos.udg.mx

(2) Marcela del Rocío Ramírez Mercado: Egresada de la Licenciatura en Diseño para la Comunicación Gráfica y de la Maestría en Diseño y Desarrollo de Nuevos Productos del Centro Universitario de Arte, Arquitectura y Diseño. Profesor de tiempo completo titular A de la Universidad de Guadalajara, con una antigüedad de 13 años, en el Centro Univer- 
sitario de Arte, Arquitectura y Diseño, impartiendo las materias de Diseño IV y Tesis II de la Licenciatura en Diseño para la Comunicación Gráfica. Mail: marcela.ramirez@cuaad. udg.mx

(3) Juan Ernesto Alejandro Olivares Gallo: Egresado de la Licenciatura en Diseño Industrial, con maestría en Desarrollo de Productos, del Centro Universitario de Arte, Arquitectura y Diseño de la Universidad de Guadalajara, Profesor de tiempo completo, titular C con 32 años de antigüedad, impartiendo asignaturas en la carrera de Diseño Industrial, y en la maestría en Diseño e Innovación Industrial. Mail: juan.ogallo@academicos.udg.mx

\section{Introducción}

El turismo religioso como actividad económica genera una derrama monetaria considerable en el estado de Jalisco. San Juan de los Lagos, es uno de los territorios de gran relevancia en el municipio, tiene más de 400 años con la celebración del día 2 de febrero la llamada fiesta de la candelaria y que llega a recibir en tan solo un día cerca de 700 mil peregrinos de diferentes partes de la república mexicana y del extranjero. Esta actividad da origen a una identidad que se refleja en los recursos gráficos aplicados para la promoción, comunicación y difusión de productos o servicios del lugar, estos manifiestan un estilo ecléctico que brinda una personalidad que se hace evidente, incluyendo las características particulares de sus visitantes, los cuales agregan una variedad de matices, ya que provienen de distintas clases sociales. Así mismo se integra la personalidad de sus habitantes que son de distintas comunidades, los cuales influyen en la identidad del pueblo. Por ello se considera relevante identificar y analizar la manera en que se constituye la identidad del municipio, mediante la suma de distintas dimensiones que se refleja en elementos gráficos que visten el entorno del municipio.

\section{El turismo en México}

En México el turismo es una actividad de económica de suma importancia, ya que esta contribuye en un porcentaje en Producto Interno Bruto -PIB-, en los estadísticos 2017 se aprecia que el turismo un aportó el 8.7\% del PIB -DATATUR, 2019-. Es decir que el turismo año con año interviene en la captación de recursos, existen distintos tipos de turismo por mencionar algunos por ejemplo turismo convencional -de descanso-, turismo por afinidad -negocios-, turismo especializado -deportes-, turismo cultural -histórico-, turismo costumbres y tradiciones -religioso-, este último es el que se abordará a continuación. El turismo religioso es un fenómeno social y económico a nivel mundial, que día a día es abordado por académicos, economistas e investigadores sociales, etc., desde ópticas distintas se puede considerar un objeto de estudio, tanto el movimiento social, el cultural así 
como los tendencias de flujos económicos, despiertan interés, para su estudio. En México es sin duda un fuerte eslabón en la cadena del sector turístico, no solo se debe al gran desplazamiento de personas que acuden a los distintos sitios donde se ubican algunas de las comunidades más representativas de la religión católica en el país, -sin por ello no considerar otros cultos religiosos-, es sin duda un movimiento económico que impacta favorablemente en las regiones aledañas a estos centros de culto; además de representar un flujo de personas y de incentivar la economía de la región, es una cadena de valor positiva que impacta otros aspectos, como son, lo cultural, lo urbano, lo arquitectónico, etcétera, es en el aspecto cultural donde se manifiesta de manera particular actos que dan identidad el pueblo de mexicano, de manera singular la religión católica impuesta por los conquistadores, dio un giro a las manifestaciones de culto del pueblo originario, señalados en su momento como paganos, por los primeros católicos, ahora estas manifestaciones de la cultura e identidad del mexicano, son producto del sincretismo, esta mezcla de expresiones, permiten una cultura muy rica y colorida.

Cada región del país tiene sus festividades religiosas, en cada rincón del país, se rinde culto a una imagen religiosa, sin embargo, las más representativas sin duda son la peregrinación al santuario de la virgen de Guadalupe el día 12 de diciembre en la ciudad de México, la celebración del día de muertos en Pátzcuaro Michoacán, el día dos de noviembre, festividad que se ha difundido en todo México, incluso trasciende fronteras y ahora se documenta y explota comercialmente fuera de toda proporción y apego a los valores religiosos sincréticos y de tradición, al grado que por hoy ha sido catalogado como un bien intangible de alto valor comercial.

Otras festividades son las relativas al culto y veneración de imágenes religiosas de todo tipo y origen, pinturas y escultura son los elementos que dominan en culto religioso, en lo relativo a las esculturas, generalmente son pequeñas piezas representativas de la virgen María, la imagen Milagrosa de la Virgen de San Juan está hecha de una mezcla de pasta de caña de maíz, material de uso frecuente por los artesanos de la época con la que modelaban figuras tanto zoomorfas como antropomorfas.

\section{El turismo en Jalisco}

En Jalisco las festividades más representativas son, las peregrinaciones de la de la Virgen de Zapopan, que recorre prácticamente toda la zona metropolitana de Guadalajara, la de Nuestra Señora de Talpa y la de San Juan de los Lagos; siendo las tres vírgenes que mayormente mueven a miles de creyentes, sin embargo la virgen de Santa Anita, de la feligresía de Tlajomulco también tiene muchos fieles devotos ya que se le atribuye gran cantidad de milagros, es visitada en su santuario por una gran cantidad de fieles, no obstante es, la de San Juan de los Lagos la segunda imagen religiosa más visitada en el País, solo después de la virgen de Guadalupe en la ciudad de México.

Los datos que esgrimen las autoridades municipales hablan de entre setecientos mil, a un millón de peregrinos en tan solo 2 días al año, el 1 y 2 de febrero, estos peregrinos provienen de varios estados de la república principalmente de Guanajuato, Querétaro, Guerre- 
ro, el estado de México, Zacatecas, Aguascalientes, Michoacán e Hidalgo, pero otra gran cantidad de peregrinos son visitantes de Estados Unidos de Norteamérica, toda esta gente demanda de atención y servicios, por muy elementales se requiere contar con la infraestructura, que facilite las necesidades y requerimientos de los turistas, comida, hospedaje, transporte, y una gran cantidad de necesidades deben ser solventadas, tanto por particulares como por autoridades municipales, puesto que representa además del servicio un flujo económico muy importante, ligado a este movimiento sociocultural, como en cualquier parte del mundo, en la página de internet de El Economista afirmó José Manuel López Campos (2019) que el turismo religioso es importante y para México no es la excepción, porque cada año deja una derrama económica de al menos 10,200 millones de pesos, de acuerdo con cifras del Senado de la República.

\section{El turismo en San Juan de los Lagos}

San Juan de los Lagos se ubica en la región Altos norte del estado de Jalisco como se aprecia en la figura 1, con una población de 43,000 habitantes, esta región fue habitada por los Nahuas antes de la conquista.

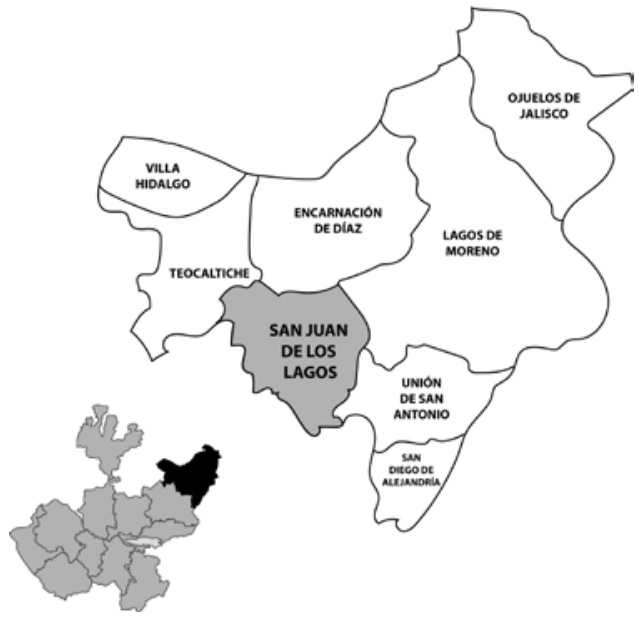

Fig. 1: Mapa San Juan de los Lagos (IIEG, 2012, s/p.). 
Toponimia: Antes de la conquista esta región fue habitada por los nahuas hacia la segunda mitad del siglo XII (quizás en 1164, aunque otras fuentes señalan el año de 1189). Se cree que en sus orígenes fue un señorío libre y que posteriormente perteneció a un señorío tecuexe cuyo su asiento estaba en Metzquititlán: lugar donde abundan los mezquites. Así a finales del año 1544, fray Miguel de Bolonia, se da a la tarea de repoblar Mezquitatlán que se denominó San Juan Bautista de Mezquititlán.

Hacia fines del siglo XVI ya había un grupo de chozas de naturales que tenían una ermita pequeña en donde hoy está la población. En la capilla, los indígenas ya evangelizados guardaban rústicamente una imagen de la virgen cuyo origen es causa de controversia, ya que mientras algunos cronistas e historiadores afirman que fue entregada a los indígenas por fray Antonio de Segovia otros afirman que fue fray Miguel de Bolonia el que trajo la imagen de la virgen al repoblar el caserío de Mezquititlán (Espiritu, 2015).

El rey Carlos IV expidió una Real Cédula en 1797 concediéndole a la villa de San Juan "el privilegio de una feria anual perpetua enteramente franca y libre de todo derecho, alcabala, arbitrio y peaje" (Espiritu, 2015, s/p. ).

En el año de 1824, San Juan de los Lagos se constituyó en departamento siendo cabecera del mismo y comprendió a los ayuntamientos de la Villa de Encarnación, de Jalostotitlán -santuario que ha venido creciendo después de la canonización de Santo Toribio Romo-, y el de San Miguel el Alto. En esa misma disposición se le concedió el título de Villa de San Juan de los Lagos, que por su carácter de cabecera de departamento ya tenía ayuntamiento. En el Centro Estatal de Estudios Municipales, perfiles (2012-2015) dice que la religión mayoritariamente católica $98.3 \%$ la devoción a la Virgen María, representa uno de los principales ingresos económicos de la población, siendo el turismo religioso motor de desarrollo, ya que deriva en una serie de factores, que van desde la hotelería, gastronomía, infraestructura urbana, comercio religioso, entre otras actividades aledañas, las fiestas religiosas tienen su momento cumbre el día 2 de febrero, día de la celebración de La Candelaria, sin embargo todos los días del año la frecuencia de visitantes y peregrinos en constante, y en mayor o menor medida requieren de servicios.

Del $1^{\circ}$ al 8 de diciembre se realiza la tradicional fiesta de la Virgen. Las fiestas de la Virgen de la Candelaria, se celebran del 25 de enero al 2 de febrero, que es el día principal; con procesiones, bandas de música, diversas danzas de la Conquista y de Moros y Cristianos procedentes de varias poblaciones de la república; estas fiestas también incluyen juegos pirotécnicos y juegos mecánicos, como casi en toda festividad de la república mexicana. Estos mismos eventos se realizan en honor de la Virgen de la Asunción, del $1^{\circ}$ al 15 de agosto. Las Fiestas de la Primavera, se realizan de 15 al 31 de mayo; con corridas de toros, serenatas, bailes y peleas de gallos, y los 5 últimos días se incrementa el jolgorio. Del ${ }^{\circ} 1$ al 12 de diciembre se festeja a la Virgen de Guadalupe. Entre otras festividades están las que se realizan en el mes de mayo, mes dedicado a la Virgen María.

Esto da idea de que el flujo de turismo religioso es constante durante todo el año, el interés de los visitantes además de la obligada visita a la Catedral; Basílica de Nuestra Señora de San Juan que data del siglo XVIII.

El Dr. Alfredo Alcántar Gutiérrez, Arquitecto y Maestro en Historia de la Arquitectura Mexicana, por la Universidad de Guadalajara y Doctor en Arquitectura, Diseño y Urbanismo por la UAEM. Relata: 
El santuario se orientó al poniente y tiene una disposición barroca, al contar con planta de cruz latina, con cúpula monumental y dos esbeltas torres campanario. Cuenta con el ingreso principal alineado a la nave central y también cuenta con ingresos transversales. El espacio más sublime del edificio es el vinculado con el presbiterio, denominado camarín de la Virgen donde la tradición disponía ser la dependencia donde duerme la Virgen y se guardan sus vestidos e imágenes peregrinas (Alcántar Gutiérrez, 2019, s/p.).

Todo destino turístico/religioso, se sustenta no solo en la presencia de alguna divinidad de culto, es también importante y como consecuencia de lo primero, el recinto religioso, la arquitectura de este majestuoso santuario, representa en sí, en monumento digno de visitar y conocer, como experiencia, la propia descripción de Dr. Alcántar (2019), da testimonio de su magnificencia.

La fachada barroca es monumental y se conforma de tres cuerpos, el primero con el arco de ingreso, custodiado por columnas que a la vez enmarcan nichos para imágenes de santos. El segundo cuerpo lo conforma la ventana coral y con las mismas disposiciones en cuanto a esculturas que el inferior. El tercer cuerpo cuenta con una claraboya octagonal y nichos como los inferiores. El copete expone una imagen de Ntra. Sra. depositada en un nicho y a los costados imágenes con la disposición de santos a los costados. El remate es moldurado con semicírculos, donde el central acentúa el eje principal con una mayor altura. Las torres son del periodo neoclásico, sin embargo son sumamente elaboradas y se conforman de tres cuerpos con aberturas de medio punto a cada costado. Un pequeño tambor en sobre el último cuerpo, sostiene una media naranja con remate en linternilla, sobre la que se apoyan cruces caladas de gran ligereza. Las cubiertas interiores son bóvedas con nervaduras góticas, sus lunetos permiten la iluminación del recinto, colocadas a lo largo de la nave central y suman tres, más tres por crucero de la de la nave transversal, suman en total diez. La cúpula es imponente, ostenta nervaduras a manera de gajos, las cuales rematan sobre los frontones semicirculares de las ocho ventanas colocadas en cada uno de los costados del tambor octagonal.

El altar mayor es de estilo neoclásico y sustituyó a uno de manufactura churrigueresca, cuyas características se pueden revisar en el museo de la Virgen, cruzando la calle del ingreso sur. El actual altar está conformado por un baldaquino que exhibe a la imagen taumaturga de Ntra. Sra de San Juan de los Lagos y a los costados se ubican a la izquierda Sr. San Joaquín y Sra. Santa Ana. De los santuarios coloniales de la antigua Nueva Galicia, es sin lugar a dudas el de Ntra. Sra. de San Juan de los Lagos el más imponente, tanto por la majestuosidad de su imagen exterior, como por lo imponente de las dependencias con las que cuenta (s/p.).

También se visita otros edificios tanto religiosos como civiles, tales como; Palacio municipal del siglo XVIII, de un estilo neoclásico, de mediados del siglo XVIII. Parroquia de 
San Juan Bautista que data de 1648, el edificio de Correos construido en el siglo XVIII con elementos de estilo barroco, como lo son el pórtico y las ventanas, entre otros, es claro que las obras arquitectónicas predominantes son corte religioso.

El reto para quienes administran la ciudad, es brindar al turista los satisfactores que cumplan sus expectativas, que además de consumir el producto turístico, se debe poner cuidado principalmente a la experiencia religiosa, que da origen y motivo, a esta actividad, ofrecer calidad en los aspectos materiales y distinguir las necesidades inmateriales, las exigencias de esa acción religiosa que es lo que mueve al peregrino.

\section{Identidad}

La identidad proviene del latín identitas y es de idem que significa -lo mismo- (Anders, 2019) es decir que en su origen se asume como concepto idénticos a sí mismo, por tanto en Real Academia Española define identidad como "el conjunto de rasgos propios de un individuo o de una colectividad que los caracterizan frente a los demás" (RAE, 2019, s/p. ). Por tanto, el concepto de identidad tiene una dualidad en primero hace referencia que es lo mismo a los demás, es decir son las coincidencias que se tienen con otra persona o lugar y en segundo dice es el conjunto de rasgos que lo hacen único. Esto coincide con la postura de Luis Villoro (1998) al determinar que el concepto de identidad es multívoco, en donde la identidad primero está constituida por las notas que lo singularizan ante los demás y en segundo permanecen en él mientras sea el mismo objeto.

$\mathrm{Al}$ retomar el concepto de identidad aplicado a un estado o pueblo se formaría en primer sentido reconocer el territorio ocupado, demografía, lengua, instituciones sociales, rasgos culturales, así como su historia. En segundo sentido está el significado, el cual se construya a partir de dos perspectiva; la perspectiva externa, es la idea colectiva que tienen los foráneos sobre el lugar y la perspectiva interna, está la idea que se tienen los lugareños sobre ellos. Este segundo sentido se construye con valores y así lo que nombra Villoro "El 'sí mismo' colectivo... que se construye a partir de creencias, actitudes, comportamientos de los grupos" (1998, p. 55). Por tanto, la identidad de un pueblo se constituye por su referente histórico, geográfico y sociales, así mismo los valores que se reflejan en los distintivos de su cultura.

De igual forma Gilberto Giménez (2005) enuncia que la identidad en el plano de los grupos, es la suma de la percepción colectiva de un nosotros homogéneo, estabilizado por el tiempo, por aposición de los otros en función del reconocimiento de los rasgos, caracteres y marcas compartidos en la memoria colectiva. Por lo consiguiente, la identidad se apoya en la serie de criterios, marcas o rasgos diferenciales, los cuales permiten diferenciar y acentuar los contrastes. Es ahí donde surge la pregunta ¿Cómo se puede iniciar a construir la identidad?, se puede retomar el planteamiento de Joan Costa (2004) la identidad se define mediante tres parámetros 1) ¿qué es? o ¿quién es?, 2) ¿qué hace? o ¿para qué sirve? y 3$)$ ¿dónde está?, lugar u origen. Estas tres preguntas permiten ayudar a definir las tres percepciones identitarias, es decir la respuesta a las tres preguntas darán la identidad de en una sola cosa, persona o lugar. Por ejemplo; El Tequila, es una bebida alcohólica su lugar 
de origen Tequila, Jalisco, México. Al seguir las tres preguntas se puede llegar a tener las percepciones identitarias y formar las bases de la identidad.

Así mismo Joan Costa (2004), argumenta que la identidad es un instrumento privilegiado, ya que es único, exclusivo y distintivo, por lo consiguiente describen los cinco integrantes sensibles de la identidad -verbal, visual, cultural, objetual y ambiental-, es importante puntualizar que en origen el autor lo orienta a la Identidad corporativa de una empresa, pero guardando las formas, también permitirá el análisis de un lugar o pueblo. A continuación se describen estos integrantes:

Identidad Verbal: El primer signo de una identidad empresarial es el lingüístico es decir el nombre, esté el signo verbal identitario, es importante el registro de la propiedad y ampararlo ante ley, esto permite legalmente las denominaciones sociales y marcarias en la medida que las formas verbales sean originales, es decir que no existan otros nombres parecidos o con los cuales se puedan confundir, al definir la identidad diferencial a través del nombre, permite su identificación y evidenciar la diferencia con sus semejantes.

Identidad Visual: Es la naturaleza visual, que si se hace referencia al signo de identidad, se cree que sólo y exclusivamente a la comunicación gráfica: como son los logotipos, los símbolos, tipografía y colores, pero en realidad es un panorama más amplio y global, es decir no solamente el nombre y la marca. En realidad la Identidad visual se desarrolla en todas las posibles manifestaciones y comunicaciones, los cuales están ligados a la percepción visual y de la memoria, de este modo la empresa es un ente más allá a las marcas y a los productos o servicios, sino la empresa como una institución, responsable ante su público. Se manifiestan en las emociones y de experiencias funcionales a través de las interacciones visuales.

Identidad Cultural: Esta toca directamente a la interacción persona a persona, si se habla de una empresa es la interacción directa con el cliente, es aquí donde el cliente vive la conducta de la empresa de manera directo y en primera persona. Por tanto la identidad Cultural, es la evidencia de lo que la empresa emite y la conducta práctica, experiencia emocional. Ya que comunicación es más fuerte que las acciones, por tanto se mide entre los mensajes que la empresa emite y la conducta que practica.

De acuerdo a Bourlon (2009) la identidad cultural es el conjunto de rasgos que permiten a un grupo reconocerse en cuanto su originalidad y diferencia a los demás, por tanto está vinculado a zona geográfica, grupo lingüística, étnico, creencias, etc. Es decir, la identidad cultural es de suma importancia para el diseño gráfico, ya que permite extraer los conceptos formales y estéticos.

Identidad Objetual: Hace referencia a la personalidad que la empresa proyecta a través de los productos y objetos que fabrica o venden, se evidencia primero mediante el estilo y la estética del exterior del producto u objeto, esta es la percepción del objeto y después la función. Con ello en primer lugar el reconocimiento de la identidad marcaria mediante la percepción y en segundo lugar por el contacto físico con el objeto y la sensibilidad del tacto. Identidad Ambiental: Uno de los signos identitarios de la empresa, es el lugar donde está, se denomina la identidad del lugar en donde se vive la experiencia total, ya que se puede propiciar emociones, sensaciones y experiencias. Se aprecia mediante el ambiente que el público vive y que forma parte la imagen global de la empresa, es la identidad del lugar donde se viven las experiencias totales cliente/empresa. 
Estas dimensiones sensibles de la identidad, se encuentran interconectadas, permiten en conjunto crear un todo continuo y dinámico. Esto se va construyendo en el imaginario de la sociedad y derivan en una imagen, olor, texto o un tejido que da forma mediante los recuerdos inmediatos, la identidad trasciende a la empresa, y encontramos valores y rasgos de identidad, en distintas concentraciones sociales, en algunos casos debidamente programados y trabajados y en otras, como producto de una evolución cuidada, donde se respetan elementos comunes, de usos, costumbres, y objetos, o entornos, es por ello que en algunas ciudades del mundo, es manifiesto el rasgo de identidad, en caso de la ciudad de San Juan de los Lagos, en el estado de Jalisco, y centro de gran tradición religiosa es un caso de estudio, donde se analiza desde las cinco dimensiones de la identidad propuestas por Joan Costa, que proveerán al final de una descripción identitaria de San juan de los Lagos.

\section{Identidad Verbal}

El nombre de una empresa es de suma importancia, ya que este permite a los consumidores recordarlo, es decir este provee identidad lingüística, que conforme la empresa logre posicionarse en el colectivo de los usuarios esto genera una simbiosis entre el nombre y la imagen gráfica de la empresa.

Si retomamos el nombre de un pueblo o municipio, este no surgió por una acción comercial, sino por algún suceso histórico, por los aspectos geográficos, de fauna o flora y posiblemente por la etnia o comunidad indígena que está o estuvo localizada en el sitio. En la situación el origen del nombre San Juan de los Lagos, como se describió en los párrafos anteriores el nombre es resultado de fusiones, la primera se asignó por los españoles a resultado de la conquista era San Juan Bautista Mezquititlán, el nombre originario era Mezquitlán -lugar de mezquites-, asignado por comunidad Mexica que habitaban previo a la conquista. Por tanto, los españoles en honor al santo precursor de cristo, anteponen el San Juan Bautista. Sin embargo tiempo después la corona española deja que se asienten familias españolas y se nombra Villas de San Juan de los Lagos, conforme avanzó el tiempo se elimina Villas y queda con el nombre que actualmente tiene San Juan de los Lagos.

El nombre de San Juan de los Lagos, adquiere renombre no por su actividad comercial, sino por el milagro de la Virgen de Inmaculada Concepción, este evento propició una gran veneración y es el comienzo de la actividad económica entorno a la peregrinación. Es aquí donde el nombre del pueblo se vincula a la virgen y se transforma en una identidad religiosa en donde el pueblo adopta la imagen y la imagen adopta en su nombre al pueblo, ya que no se reconoce hoy en día como la Virgen de San Juan de los Lagos.

En cuanto al nombre y su posible comparación con otro municipio de la República Mexicana, de acuerdo Instituto Nacional de Estadística y Geografía-INEGI, 2016- en el Clasificación de países; entidades federativas y municipios de los Estados Unidos Mexicanos, reporta existen 2,457 municipios. Las coincidencias con el nombre de San Juan de los Lagos son las siguientes: 1) Existen 389 municipios que inician su nombre con San, 2) De esos municipios 63 coinciden con San Juan y 3) solo un municipio coincidencia con la palabra lagos. 
Por lo cual, su nombre tiene coincidencia, pero ninguna puede propiciar confusión con el nombre y con la virgen.

\section{Identidad visual}

Es evidente que en las cercanías a la edificación del culto religioso, generalmente ubicados en los centros históricos de las poblaciones los rasgos principales de la traza urbana, los edificios principales, la nomenclatura y numeración de calles permanece casi inalterada en lo general, pero en la medida que se hace un recorrido del centro hacia la periferia, tanto el estilo arquitectónico, la traza urbana, el sistema de señalética tanto oficial como de carácter comercial se transforma en aras de transitar a la modernidad, donde no solo se incluye un estilo más actual, si no que se hace evidente la participación de profesionales, en el campo del diseño, dando señales de un manejo formal, en las sistemas de comunicación, siendo este último en donde se hace evidente la falta de un claro proyecto de manejo de marca e identidad.

Los elementos urbanos que permiten una adecuada comunicación con los usuarios, deben partir de principios de diseño y de comunicación gráfica y objetual, no sólo bajo criterios estéticos, que en el caso que nos ocupa son muy discutibles, y son prueba de la ausencia de criterios de diseño, como veremos el análisis más adelante, encontraremos una gran variedad de estilos y sistemas de comunicación, diversidad de fuentes tipográficas, manejo indiscriminado de materiales, colores, se destaca en este mosaico de señales el eclecticismo, y proliferación creativa, haciendo del paisaje urbano un verdadero muestrario de señales que no guardan orden o razón aparente. Se encuentran estilos clásicos, modernos y contemporáneos a determinada época, que son resultado de políticas públicas fallidas, que responden a periodos de autoridades municipales, estatales y en su caso, federales.

Buscando una descripción general, se puede encontrar en lo referente a las placas de calle, que por su material hay de lámina, cerámica, cantera, aluminio y hierro; por su proceso, se encuentran impresas, rotuladas a mano, labradas, o de fundición. Por su forma se observan rectangulares de manera genérica, pero en distintas proporciones, predominando el sentido horizontal respecto a su cara mayor, en algunos casos con variaciones, tales como esquinas con corte en chaflán, o romas, en otros casos con adornos a manera de heráldica, por sus dimensiones de manera general conservan un proporción adecuada en relación a ser visibles, sin embargo diferentes entre sí, por su manera de ser instaladas, se ven adosadas a los muros de las construcciones mediante distintos sistemas, desde las que se reciben con materiales aglutinantes o de anclaje químico, como las de fijación mecánica también se encuentran instaladas en postes diversos, ya sea de alumbrado público, o semáforos y de manera ocasional mediante soporte ex profeso, a manera de banderola.

Como se puede apreciar, no existe un programa que de sentido ni uniformidad al sistema de señalización de las calles de esta población, generando gran confusión al visitante, y evidenciando la falta de un programa de diseño para un adecuado manejo, se los sistemas de comunicación gráfica. 

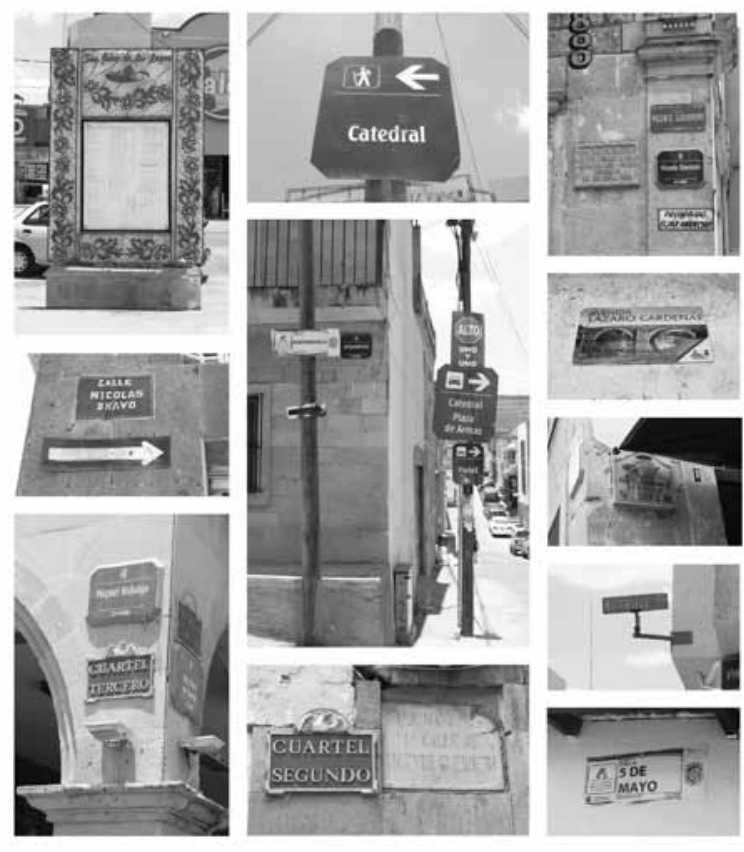

Figura 2. Placas de nomenclatura, informativas y de tráfico (Cisneros, 2019).

\section{Identidad Cultural}

Esta dimensión dentro de una empresa es la interacción persona a persona, es decir cliente - empresa, por tanto, es la forma en que se conduce o es la experiencia que ocasiona en los clientes, en esta interviene una perspectiva más emocional y pocas veces racional. Por tanto, enfocado a la Identidad de un pueblo, la Organización de Estados Iberoamericanos determina que la cultura no se debe ver como un factor de la vida social en asuntos patrimoniales o artísticos, sino del ser del devenir del interés del público y político que haga del recurso cultural un catalizador de los procesos de desarrollo (OEI, 2006). Es decir, que la cultura no es un aspecto referente a actividades de carácter artístico, sino se construye mediante inmuebles, usos y costumbres, gastronomía, ritos y la vida cotidiana.

En el caso específico del pueblo de San Juan de los Lagos, se aprecia su cultura primero en las festividades como la celebración de la Candelaria, las cuales son a finales de enero y principios de febrero, asimismo la fiesta de primavera que se realizan en mayo, estas festividades conservan tradiciones y difunden usos y costumbres, como las procesiones acompañadas con bandas de música y danzas que hacen alusión a la conquista.

El segundo es la comunidad, en sí los lugareños, que en su mayoría se dedica al comercio $\mathrm{o}$ actividades que directamente o indirectamente se vinculan a productos o servicios re- 
ferentes a la Virgen, se pueden apreciar en los pasillos cerca a la basílica a vendedores con un acento cantado, el cual los hace ser peculiares en su forma de dirigirse al cliente, para ofrecerte artículos relacionados a la virgen -figuras, medallas, rosarios, etc.-, dulces o la tradicional cajeta, que se acercan con una muestra en una pala pequeña de madera. Otros personajes que son emblemáticos son los jóvenes que formalmente son los asistentes turísticos o bien conocidos como perreros, se encuentra en las entradas del pueblo, ellos contactan al visitante que llega en vehículo particular con la preguntan ¿amigo, usted va a la basílica?, con la intención indicar por dónde puedes llegar y lograr llevarte al estacionamiento que tienen convenio, ellos corren delante de tu carro o mediante su motocicleta te guían. Estas particularidades hacen que sean únicos, por ende muestran la cultura que emiten por ser y que por ende es parte de la identidad del pueblo.

Pero, si nos vamos a revisar qué opinan del pueblo, en este tiempo en donde portales digitales, guardan registro de las opiniones de los visitantes, al revisar uno de estos sitios que orientar al viajero, es decir TripAdvisor México $_{\circledast}(2019)$ se encuentran los siguientes resultados, 109 calificaciones con excelente, 24 con evaluación muy bueno, 8 que calificaron regular y un comentario con calificación malo, estás evaluación las realizaron viajeros adscritos a la plataforma, con comentarios que describen lo bueno de su vista. En el portal Minube $_{\circledast}(2019)$ tiene una valoración de 4.6 de 5 como puntuación máxima, así como otros portales, describen al pueblo con una buena reputación, que es agradable para recomendar visitarlo y describe la interacción pueblo /visitante.

\section{Identidad objetual}

Tanto el turista ocasional, como el peregrino habitual, gustan de adquirir productos, que sean oriundos, ya sea del propio San Juan, o de la zona aledaña, sin embargo en la actualidad es difícil ubicar el origen de tales bienes con precisión, ya que la comercialización de productos de corte artesanal, sumado a la gran demanda, favorece la inclusión de productos manufacturados prácticamente en cualquier parte del país. De la inmensa cantidad de mercancías presentes en el comercio local, solo algunas artesanías o el típico dulce son realmente de la zona de los altos de Jalisco y menos aún, propios de San Juan de los Lagos, lo que genera confusión para quien verdaderamente aspira adquirir artículos originales del lugar, es muy común encontrar el dulce de leche quemada, -cajeta de leche-, que se ofrece como hecho en el lugar, sin embargo considerable producto es elaborado fuera de la población, siendo la ciudad de Guadalajara, en el mismo estado de Jalisco, el principal proveedor de dicho dulce, por otra parte, las artesanías son de orígenes varios, el estado de México y de Jalisco son los principales proveedores, Tonalá, en el mismo estado de Jalisco es una población de gran tradición de productos artesanales, es por eso que se hace complicado precisar sobre una artesanía o recuerdo propios de San Juan, no obstante se hará referencia a algunos de ellos, que por distintas razones son considerados como en recuerdo típico del lugar y elementos que proveen elementos a la identidad del pueblo. 


\section{Cajeta de leche}

Uno de los artículos representativos es el dulce de leche llamado cajeta, este se ha vuelto popular y distintivo por los visitantes, este tiene cuatro variantes natural, envinada, con tequila, nuez y vainilla, este producto se ofrece por los pasillos cercanos a la basílica. Al ser del agrado de los visitante, es común apreciar cómo adquieren cantidades considerables en botes genéricos, de distintas capacidades, el material es Polietileno de alta densidad -PEAO-, 65050 y Polietileno de baja densidad -PEBO-, 17070, hecho por proceso de inyección este contenedor de forma cilíndrica con anomalía, con cambio de diámetro en la parte superior, teniendo un ensanchamiento y reborde para engarce de tapa, en la parte superior se ubica el asa. En cuanto a la imagen gráfica como es habitual, tiene la síntesis de la Virgen de San Juan de los Lagos estampada de manera directa sobre el contenedor o impresa en vinil auto adherible, a manera de calcomanía o pegatina, y la palabra que describe el contenido que guardará el envase, con el propósito de diferenciar el producto respecto al otros similares, pero de diferente origen, casa, o razón social. Es decir una vestimenta limitada y genérica, ya que es similar en la mayoría de los negocios.

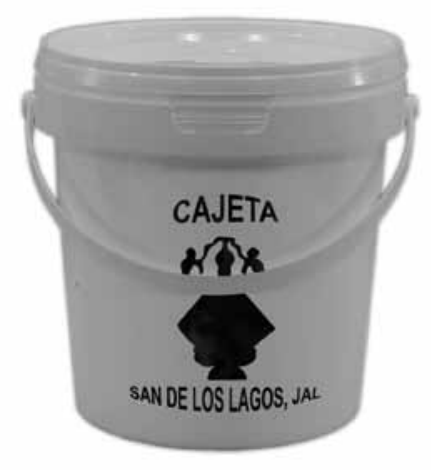

Figura 3. Envase para cajeta de leche (Cisneros, 2019).

\section{Bolsa de mandado}

La bolsa de mandado al ser un producto genérico y de origen muy antiguo, su antecedente de ésta data de la época precolombina, es posible que los asistentes a los mercados usaran canastos confeccionados de fibras naturales tales como tule, la palma, el henequén o ixtle que ya se teñían de colores, este tipo de canastos o bolsas dan origen a la típica bolsa de mandado de fibras sintéticas de uso actual, incluso con nuevos bríos se incorpora 
como efecto de las posturas ecológicas, a este artículo se le imprime mediante el proceso de serigrafía la imagen de la virgen o una imagen sintética de la fachada del santuario, acompañada de textos alusivos a la estancia es este sitio, el peregrino además de comprar los recuerdos o los antojos; al compra la bolsa para transportar sus mercancías tiene la posibilidad de dar un uso posterior al ir de compras y hacer el mandado, es sin duda un recuerdo muy típico de la población, si bien no se puede afirmar que es un producto local ya que este tipo de bolsa se encuentran en muchas ciudades -por no decir que en todas-, de la República Mexicana, si es muy de la región el que se comercialice con las imágenes típicas impresas.

Las características de la bolsa en lo general se podría decir que son de dimensiones que fluctúan entre los $45 \mathrm{~cm} \mathrm{x} 45 \mathrm{~cm}$, a $15 \mathrm{~cm}$ x $10 \mathrm{~cm}$, y de materiales como lo es la malla textil de hilo plástico, pudiendo ser polipropileno, o en monofilamento de polietileno de alta densidad. La forma es rectangular y dispuesta en el eje vertical de su lado más corto en posición superior e inferior con apertura en la parte superior y cerrado por sus tres lados restante, consta de dos asas de plástico tubular, adosada a la malla mediante remaches y generalmente reforzada en el perímetro de la boca con una tira de plástico laminado a manera de bies.

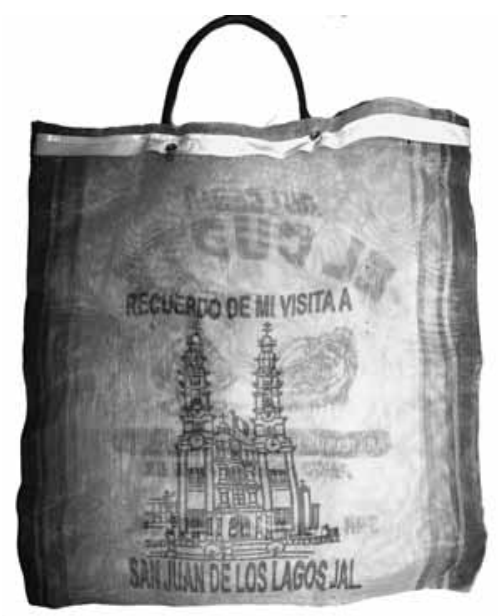

Figura 4. Bolsa para mandado en malla textil plástica, con impresión en serigrafía (Cisneros, 2019).

\section{Artículos religiosos}

No se podría entender una visita al segundo santuario más visitado de México, sin la presencia de una interminable cantidad y variedad de artículos relacionados, en primer lugar con la representación de la Virgen de San Juan de Los Lagos, y o cualquier otra imagen 
alusiva a la cristiandad, sin lugar a dudas, es la medalla, el artículo que acapara la atención de los fieles visitantes, es posible encontrarla en muy distintas versiones, tamaños y materiales, desde oro de 24 kilates, con incrustaciones de piedras preciosas, pasando por otras aleaciones, de materiales semipreciosas, o de metales como el aluminio y otros de menor calidad, figurillas y material impreso de toda índole, complementan la diversidad de oferta, por ello es casi imposible describir con precisión un artículo, sin embargo este fenómeno se replica en cualquier lugar del mundo, la manufactura puede ser local, nacional o global y es ahora fácil encontrar productos de conceptos tan propios de una región o país pero de origen asiático por generalizar, este fenómeno es común del turismo religioso, $\mathrm{y}$ es posible encontrar el recuerdo de acuerdo al gusto y el poder adquisitivo del peregrino.
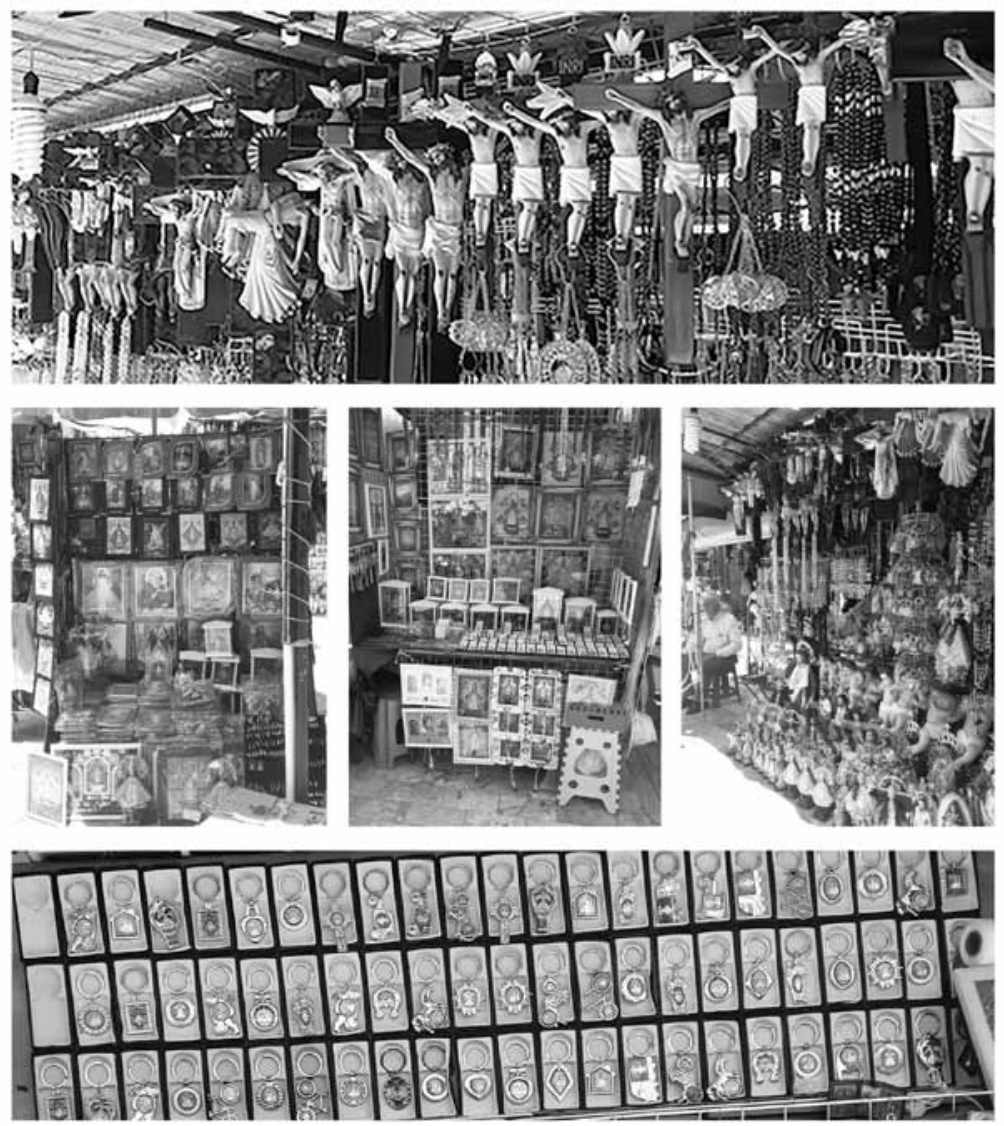

Figura 5. Artículos religiosos (Cisneros, 2019). 


\section{Identidad ambiental}

Las calles aledañas a los recintos religiosos se han transformado en zonas comerciales de alta plusvalía, no se encuentra una sola edificación que no se haya convertido en comercio, la venta de productos, de toda índole es constante y el comercio formal compite con el informal que a manera de tianguis se instala en cualquier espacio disponible, invadiendo toda vialidad, dulces regionales, recuerdos religiosos, maletas, ropa y comida, discos y música, todo es posible encontrar, sabores, olores, y colores en un festín a los sentidos, como casi en cualquier población del país es común disfrutar de este estilo de comercio, donde música y vendedores elevan su volumen sonoro para llamar la atención de los transeúntes, y lograr hacer un trato comercial, tanto los visitantes, los propios o extraños camina por las calles en busca del recuerdo, el buen sabor o la prenda de ocasión.

Este estilo de vida en las zonas adyacentes a los recintos religiosos ha modificado el espacio urbano, no solo en su fisonomía, también de alguna manera la infraestructura urbana se transforma, lo que en tiempo fue tranquilidad y armonía cromática, se transforma en algarabía y estridencia de colores, los materiales tradicionales de edificios, como cantera y adobe se mezclan con el aluminio y el plástico, los soportes de antaño de madera y fierro forjado ahora son de perfiles metálicos comerciales, donde la esencia artística y la calidez del trabajo hecho a mano, ha cambiado por el producto común de poca calidad, rótulos y carteles que entonces fueron hechos por las manos diestras de rotulistas, hoy se mezclan con la impresión y rotulación digital, aunque el letrero espontáneo el diseño vernáculo no dejan de estar presentes, dando ese particular estilo que en ocasiones provoca risas involuntarias, o que son la intención del comerciante convertido en rotulista o diseñador vernáculo.

La transformación y la necesidad de transitar a la modernidad conlleva el riesgo de perder muchos valores artísticos, culturales y de identidad de las ciudades, la dualidad no es fácil, el peregrino viaja para encontrarse con el santuario que debe brindar la experiencia espiritual, única, y espera de manera inconsciente vivenciar el espacio sagrado que en su imaginario tiene, -generalmente trasladarse en el tiempo, y encontrar inalterados los rasgos característicos de un pasado-, pero fuera del acto religioso demanda de servicios paganos de calidad o folclore, que solo las ciudades modernas pueden ofrecer, estos servicios obligan a las autoridades y a los particulares, a migrar, de un estilo, genérico donde se pierde todo rasgo de particularidad e identidad local.

A continuación se muestran varias fotografías de establecimientos o negocios que se ubican en las calles aledañas a la basílica y otras en la periferia, en estas imágenes se puede apreciar en cada uno de los negocios la manera de promocionarse o el nombre del establecimiento, las características son muy peculiares en cada uno de ellos, ahí se refleja el ingenio de los propietarios para desarrollar su propia identidad y dar una solución gráfica y estética con una combinación de técnicas, audacia y originalidad.

Cuatro géneros bien definidos dominan esta ensalada de imágenes de gráfica funcional: rótulos, carteles, murales y etiquetas; y cada uno de ellos guarda claros paralelismos con otras categorías del diseño gráfico contemporáneo. Los rótulos son esencialmente composiciones tipográficas, que en ocasiones 
se acompañan de viñetas. Los murales constituyen ilustraciones públicas que, producidas a gran escala, ilustran eventos o decoran establecimientos y están emparentados, a su manera con la escuela del muralismo mexicano. Las etiquetas y empaques continúan una larga tradición que se remonta, un par de siglos atrás, a los orígenes del arte comercial y publicitario (Mena, 2001, p. 9).

Se puede apreciar que los rótulos, de los comercios más cercanos o en las inmediaciones a la catedral, sea cual sea el tipo de negocio, conserva rasgos característicos de una tipografía estudiada, o al menos reflexionada, donde prevalece el tipo de fuente con serif generalmente, rotuladas a la vieja escuela, ya sea directa sobre el muro, o en algún tipo de soporte. Mientras que los comercios más alejados, utilizan fuentes más variadas y modernas, donde destacan las fuentes de palo seco, las aplicaciones en acrílicos u otro tipo de materiales y soportes, rotuladas por medios digitales.
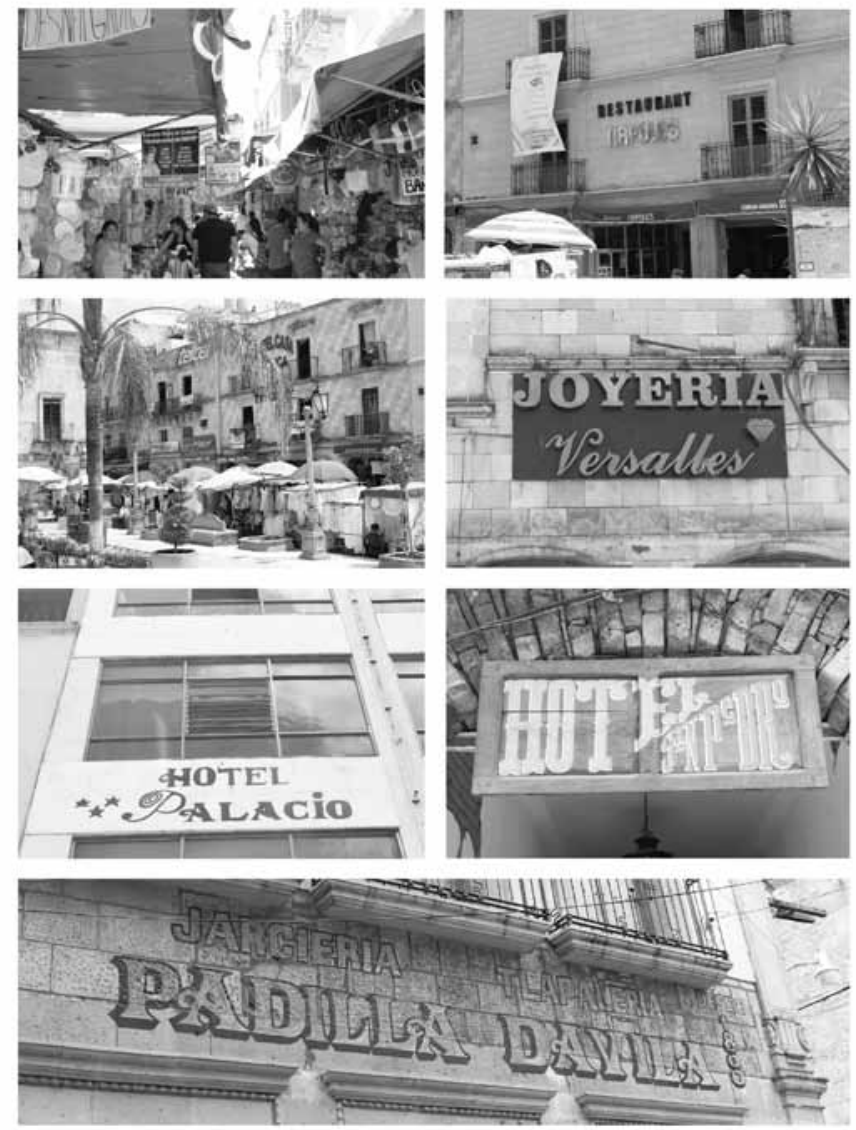

Figura 6. Rótulos y anuncios en las calles aledañas a la Basílica (Cisneros, 2019). 

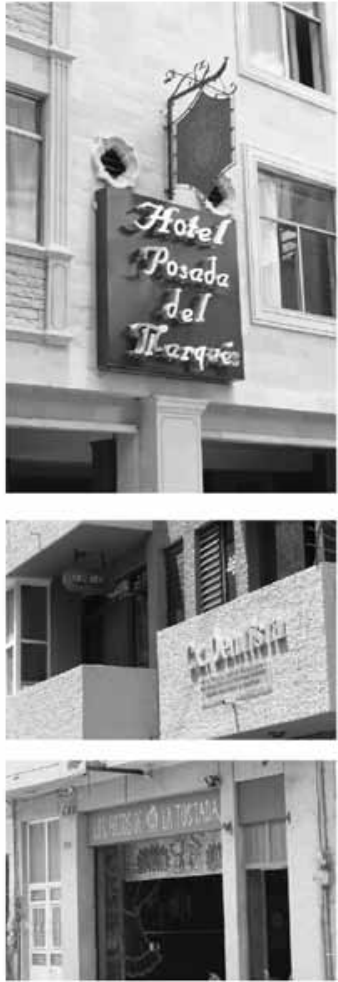
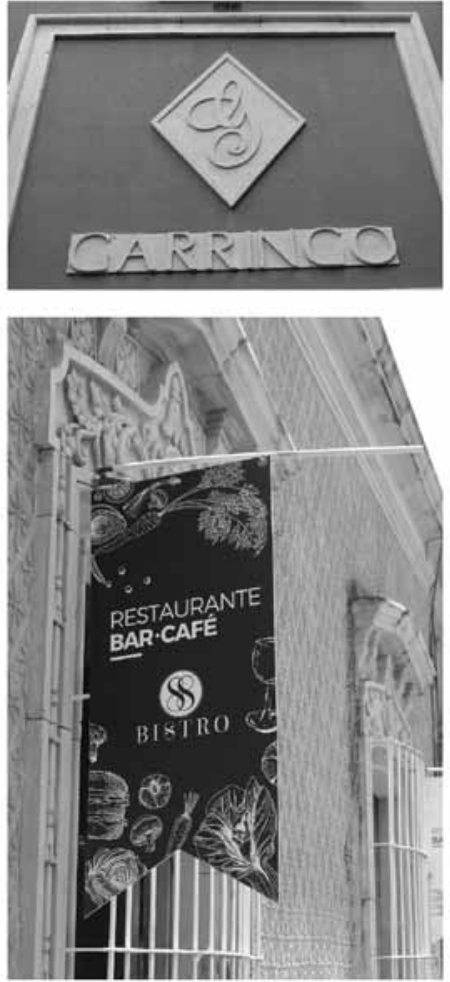
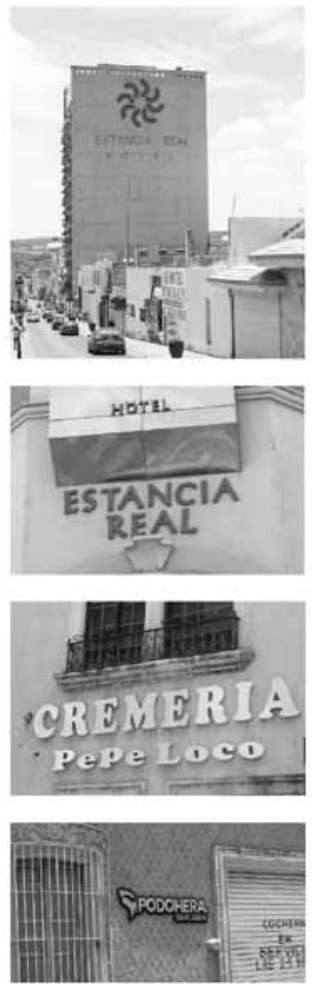

Figura 7. Rótulos y anuncios en las calles en la periferia de la Basílica (Cisneros, 2019).

\section{Conclusiones}

Encontramos una población que posee una imagen cimentada en el ámbito místico, es un claro ejemplo de un espacio de turismo religioso, y se encuentra dentro de los primeros lugares referentes al rubro de las peregrinaciones en México.

$\mathrm{Al}$ realizar el análisis, de las cinco dimensiones que construyen una identidad, se aprecian dos de ellas que son definidas y muestran los rasgos identitarios que destacan, como lo es el verbal y el cultural, ya que son resultado de sucesos sociales e históricos, es por ello que estos no son modificables principalmente el verbal, que se refiere al nombre. En cuanto a lo cultural, este va mutando por el cambio generacional, siendo paulatino e incremental. Son las nuevas generaciones quienes buscan exaltar las bondades de San Juan de los Lagos, esto sucede de manera paulatina, invariablemente en torno a la imagen de la virgen. 
Sobre las dimensiones visuales, ambientales y objetuales, es importante propiciar un cambio que permita reforzar la identidad que ya posee el municipio en el ámbito del turismo religioso, como referente importante se tiene las calles de San Juan de los Lagos, se nota una conexión en el gusto decorativo de los moradores, en las paredes ilustran sus ilusiones con el fin de comunicar servicios y mercancías o significar, y lo hacen con escepticismo. Se puede pensar en intervenciones que en ocasiones son cuidadas y en otras desatendidas, es así que en cada uno de los espacios, podemos ver para el caso de la imagen cuidada, que se tuvieron efectiva atención en las decisiones de seleccionar una tipografía, un color, una imagen o hasta un ornamento y crear formas sorprendentes; en el otro sentido, no se consigue una propuesta apropiada, pero en ambos casos sin tener en cuenta el detalle en su conjunto, no existe unificación de estilo e identidad, solo se intuyó en la combinación de utilidad práctica colocando un cierto sentido de orden y equilibrio en todo caso, para su mejor apreciación, es así que la propuesta gráfica, si bien es interesante como objeto de estudio del diseño vernáculo, dista mucho de ser un proyecto identitario para un localidad tan importante en lo referente al turismo y su implicaciones.

En cuanto a los objetos a diferencia de las paredes o anuncios, se carece de uno de los elementos fundamentales como lo es considerar la identidad, evidencia clara de la falta de un proyecto de solución integral que dé respuesta a la búsqueda del turista y permita incrementar el valor de los productos, y no estamos aludiendo a un valor monetario, si no de apreciación estética y referente cultural, no se encuentra una razón, en cada producto que se supusiera oriundo, más allá de lo sólo funcional.

Se hace evidente que la falta de proyectos de diseño de identidad, impide un adecuado uso de marca, que admita estimular al productor local. Es claro que sin integrar un programa de diseño o manejo de identidad, como pudiera ser una marca colectiva o alguna otra modalidad que les permitiera un control integral y les aporte por una parte la seguridad que transmitan al consumidor de adquirir un producto de calidad y manufactura local, y por otra trabajar en los criterios de diseño profesional, que logren establecer una identidad, ya sea por sector, por giro comercial, o por colectividad de índole comercial o institucional, se verán, en desventaja competitiva.

\section{Referencias Bibliográficas}

Anders V. (2019). Etimología de identidad Recuperado de http://etimologias.dechile. net/?identidad

Bourlon, L. (2009). Hacia la concepción de un sentido de identidad en el diseño gráfico mexicano p: 56 - 66 Actas de Diseño No7 IV Encuentro Latinoamericano de Diseño "Diseño en Palermo" Comunicaciones Académicas : Buenos Aires.

Costa, J. (2004). Dircom on line: el master de dirección de comunicación a distancia. Grupo Editorial Design.

DATATUR (2019). Compendio estadistico del turismo en México 2017, Recuperado el 1 de julio de 2019 https://www.datatur.sectur.gob.mx/SitePages/CompendioEstadistico.aspx 
Espíritu. R (2015). Gobierno del estado de Jalisco. Recuperado el 1 de julio de 2019 de https:// www.jalisco.gob.mx/es/jalisco/municipios/san-juan-de-los-lagos

Giménez, G. (2005). Teoría y análisis de la cultura. México: CONACULTA.

INEGI (2016). Catálogo Único de Claves de Áreas Geoestadísticas Estatales, Municipales y Localidades recuperado 20 de Junio 2019 de https://www.inegi.org.mx/app/ageeml/

López, J. (2019). El economista. Recuperado el 2 de julio de 2019 de https://www.elecono mista.com.mx/turismo/Turismo-religioso-deja-al-menos-10200-millones-de-pesos-alano-a-Mexico-20190421-0027.html

Mena, J. (2001). Sensacional de diseño mexicano. México: CONACULTA.

OEI (2006). La Cultura y el Turismo como Medios de Desarrollo Socioeconómico obtenido el 28 de Julio de 2019 de https://www.oei.es/historico/cultura/culturamhmejia.htm

Real Academia Española (2019): Diccionario de la Lengua Española Identidad Recuperado de https://dle.rae.es/?id=KtmKMfe

TripAdvisor México (2019). Basílica de San Juan de los Lagos, obtenido el 28 de Julio de 2019 de https://www.tripadvisor.com.mx/Attraction_Review-g2312118-d2290739-Reviewsor10-Basilica_de_San_Juan_de_los_Lagos-San_Juan_de_Los_Lagos.html

Villoro, L. (1998). Sobre la identidad de los pueblos. Estado plural, pluralidad de culturas, 63-78.

\begin{abstract}
Religious tourism or pilgrimage tourism is one of the activities that generates a considerable economic impact in the state of Jalisco. One of the sites of great importance that the state has is the municipality of San Juan de los Lagos, which is more than 400 years old with the celebration of February 2 the so-called Candlemas festival and which receives about 700 thousand pilgrims from different parts of Mexico and foreigners. Therefore, its activity generates or fosters an identity that is reflected in the graphic resources applied to the promotion, communication and dissemination of products or services of the place, these show an eclectic style that provides a personality that is evident in the particular characteristics of its visitors, which add a variety of nuances, since they come from different social classes. It also integrates the personality of its inhabitants who are from different communities, which influence the identity of the people. It is interesting to identify and analyze the way in which the identity of the municipality is constituted, by means of the sum of different factors that are reflected in graphic pieces or graphic elements, that dress the environment of the municipality.
\end{abstract}

Keywords: Religious tourism - Identity - Eclectic style - Graphic elements - Stylistic codes.

Resumo: Turismo religioso ou turismo de peregrinação é uma das atividades que gera um impacto econômico considerável no estado de Jalisco. Um dos locais de grande importância que o estado possui é o município de San Juan de los Lagos, que tem mais de 400 anos com a celebração de 2 de fevereiro do chamado festival Candlemas e que recebe cerca de 700 mil peregrinos de diferentes partes do México e estrangeiros. Portanto, sua 
atividade gera ou fomenta uma identidade que se reflete nos recursos gráficos aplicados à promoção, comunicação e divulgação de produtos ou serviços do local, estes mostram um estilo eclético que proporciona uma personalidade que se evidencia nas características particulares de seus visitantes, que adicionam uma variedade de nuances, uma vez que eles vêm de diferentes classes sociais. Também integra a personalidade de seus habitantes que são de diferentes comunidades, que influenciam a identidade das pessoas. Interessante identificar e analisar a forma como se constitui a identidade do município, por meio da soma de diferentes fatores que se refletem em peças gráficas ou elementos gráficos, que vestem o ambiente do município.

Palavras chave: Turismo religioso - Identidade - Estilo eclético - Elementos gráficos - Códigos estilísticos.

[Las traducciones de los abstracts fueron supervisadas por el autor de cada artículo] 